\title{
Conservação in vitro de Cochlospermum regium (Schrank) Pilg.- Cochlospermaceae sob regime de crescimento mínimo
}

\author{
CAMILLO, J. ${ }^{1}$; SCHERWINSKI-PEREIRA, J.E. ${ }^{2^{*}}$; VIEIRA, R.F. ${ }^{2}$; PEIXOTO, J.R. ${ }^{1}$ \\ ${ }^{1}$ Universidade de Brasília. Instituto de Ciências Ala Sul, Cx. Postal 4508, CEP: 70910-970, Brasília, DF; ${ }^{2}$ Embrapa \\ Recursos Genéticos e Biotecnologia, Núcleo Temático de Recursos Genéticos, PqEB, Av. W5 Norte (final), Caixa \\ Postal 02372, CEP: 70770-900, Brasília, DF. *jonny@cenargen.embrapa.br
}

\begin{abstract}
RESUMO: Cochlospermum regium é uma planta de áreas de cerrado, caatinga e pantanal. $\mathrm{Na}$ medicina popular é conhecida por "algodão-do-campo" e suas raízes são utilizadas para o tratamento de infecções uterinas, intestinais, gastrite, úlceras e artrite. Atualmente, o extrativismo e a destruição dos habitats naturais colocaram o algodão-do-campo na lista de espécies medicinais nativas prioritárias para conservação ex situ. O objetivo deste trabalho foi desenvolver uma metodologia para a conservação in vitro do algodão-do-campo e fornecer subsídios para estudos de micropropagação da espécie. Sementes de algodão-do-campo foram testadas quanto à germinação in vitro pela escarificação ou não das sementes em ácido sulfúrico e inoculação em meio de cultura MS. Para a conservação in vitro, segmentos nodais retirados das plântulas germinadas in vitro foram avaliados por 90 dias sob três regimes de temperatura $\left(10,20\right.$, e $\left.25^{\circ} \mathrm{C}\right)$ e em três concentrações de meio WPM $(1 / 2,3 / 4$ e pleno). Verificou-se que sementes escarificadas apresentaram percentual de germinação in vitro de $93,3 \%$ aos 30 dias, valor significativamente superior aos $13,3 \%$ observados nas sementes não escarificadas. A conservação da espécie in vitro mostrou-se viável, desde que as culturas sejam mantidas em câmara de crescimento a $20^{\circ} \mathrm{C}$ em meio de cultivo $1 / 2$ WPM. Sob estas condições os explantes mantiveram um crescimento mínimo e percentual de sobrevivência de $100 \%$, após três meses de avaliação.
\end{abstract}

Palavras-chave: Algodão-do-campo, conservação in vitro, micropropagação, germinação, plantas medicinais

\begin{abstract}
In vitro conservation of Cochlospermum regium (Schrank) Pilg.Cochlospermaceae under minimal growth storage. Cochlospermum regium is a plant from cerrado, caatinga and pantanal areas. In popular medicine, it is known as "algodão-do-campo" and its roots are used to treat uterine and intestinal infections, gastritis, ulcers and arthritis. Nowadays, extraction activities and the destruction of natural habitats has made "algodão-docampo" one of the major native medicinal species for ex situ conservation. The aim of this work was to develop a methodology for the in vitro conservation of "algodão-do-campo", contributing to studies on the micropropagation of this species. In vitro germination was evaluated in "algodãodo-campo" seeds subjected to scarification or not with sulfuric acid and inoculation in MS medium. For in vitro conservation, nodal segments from in vitro-germinated seedlings were evaluated for 90 days at three temperatures $\left(10,20\right.$ and $\left.25^{\circ} \mathrm{C}\right)$ and three WPM medium concentrations $(1 / 2,3 / 4$ and full-strength). Scarified seeds presented $93.3 \%$ in vitro germination at 30 days of cultivation, a significantly higher value than the $13.3 \%$ observed for non-scarified seeds. The in vitro conservation of "algodão-do-campo" showed to be viable once cultures are kept in a growth chamber at $20^{\circ} \mathrm{C}$ in $1 / 2$ WPM medium. Under such conditions, the explants presented a minimal growth and $100 \%$ survival after three evaluation months.
\end{abstract}

Key words: "Algodão-do-campo", in vitro conservation, micropropagation, germination, preservation, medicinal plants

Recebido para publicação em 14/05/2008

Aceito para publicação em 07/10/2008

Rev. Bras. PI. Med., Botucatu, v.11, n.2, p.184-189, 2009. 


\section{INTRODUÇÃO}

O cerrado é o segundo maior bioma do Brasil e de acordo com estudos da Conservation International restam intactos apenas $20 \%$ de sua cobertura original (Alho, 2005). Mendonça et al. (1998) relatam a ocorrência no cerrado de mais de 7.000 espécies de plantas superiores e estima-se que deste total, cerca de 4.400 sejam endêmicas.

Dentre as espécies endêmicas do bioma cerrado pode-se citar o algodão-do-campo [Cochlospermum regium (Mart. ex Schrank) Pilger], que é arbusto de ocorrência freqüente nas áreas de cerrado da região centro-oeste do país. Na medicina popular as raízes são utilizadas para o tratamento de infecções uterinas, intestinais e ovarianas, gastrite, úlceras, artrite e afecções da pele. Análises fitoquímica e farmacológica do extrato das raízes do C. regium demonstraram que o flavonóide kaempferol (F-52) possui propriedades analgésica e antiedematogênica (Lima et al.,1995), anti-bacteriana (Oliveira et al., 1996), antioxidante, mutagênica e citotóxica (Toledo et al., 2000; Nunes \& Carvalho, 2003; Nunes et al., 2003; Castro et al., 2004). Ceschini \& Campos (2006) demonstraram os efeitos do extrato aquoso preparado com o pó das raízes de C. regium no tratamento de artrite reumatóide.

A crescente demanda da indústria farmacêutica por produtos de origem vegetal constitui uma ameaça à conservação de plantas medicinais, na forma como vem sendo atendida. Alguns dados sobre comércio de plantas medicinais nativas têm mostrado que mais de $50 \%$ das espécies nativas exportadas pelo Brasil são coletadas em seu ambiente natural, na forma de um extrativismo predatório que pode comprometer a sobrevivência dessas espécies e dos ecossistemas envolvidos, diante da elevada utilização de componentes das plantas essenciais para sua reprodução, como flores, frutos, sementes e raízes. Deste modo, algumas plantas medicinais nativas encontram-se ameaçadas de extinção, ou mesmo comercialmente extintas em determinadas regiões (Brito, 2003). Nestes casos faz-se necessário a adoção de medidas de conservação das espécies fora do seu ambiente natural (ex situ), que podem ser via bancos de sementes em temperaturas sub-zero ou conservadas in vitro.

As técnicas de cultura de tecidos em plantas, em alguns casos, podem representar a única estratégia para conservar estas espécies fora do seu habitat, como no caso de plantas com sementes recalcitrantes e de difícil propagação vegetativa por métodos convencionais (Roca et al., 1991; Ferreira et al., 1998).

Outra finalidade importante da cultura de tecidos é facilitar a propagação em larga escala de espécies de propagação vegetativa de importância econômica, como é feito rotineiramente para culturas como a banana, batata e cana-de-açúcar. Mas a multiplicação em larga escala também pode ser útil para espécies de onde a obtenção da matéria prima se dá por extrativismo, e o número de indivíduos na população pode não ser suficiente para atender a demanda. Neste caso, o cultivo sistematizado in vitro pode garantir a produção regular e em larga escala (Pereira, 2003).

O extrativismo e a destruição dos habitats naturais colocaram o algodão-do-campo, na lista de espécies medicinais nativas prioritárias para conservação no cerrado. O objetivo deste trabalho foi adequar uma metodologia para a conservação in vitro do algodão-do-campo e fornecer subsídios para estudos de micropropagação da espécie.

\section{MATERIAL E MÉTODO}

O trabalho foi conduzido no Laboratório de Cultura de Tecidos e Conservação de Germoplasma Vegetal da Embrapa Recursos Genéticos e Biotecnologia em Brasília, DF. As sementes utilizadas como fontes primárias de explantes foram obtidas de frutos maduros, em plantas adultas de populações nativas de algodão-do-campo coletadas no entorno do Distrito Federal. As coletas foram realizadas semanalmente entre os meses de julho e setembro de 2006.

Para o teste de germinação, as sementes foram imersas em água destilada por 48 horas, sendo a desinfestação realizada em solução de hipoclorito de sódio $(2,0 \%$ a $2,5 \%$ de alvejante sanitário comercial) por 20 minutos. As sementes foram divididas em dois sub-lotes de 30 sementes cada, sendo que no primeiro lote (T1), as sementes foram submetidas à escarificação química com ácido sulfúrico $\left(\mathrm{H}_{2} \mathrm{SO}_{4}\right)$ por 40 minutos, e no segundo lote (T2), as sementes foram inoculadas sem tratamento químico.

O meio de germinação foi o MS (Murashige \& Skoog, 1962), reduzido da metade das concentrações de sais de macro e micronutrientes, suplementado com $20 \mathrm{~g} \mathrm{~L}^{-1}$ de sacarose, $5 \mathrm{~g} \mathrm{~L}^{-1}$ de ágar (Acumedia) e $2 \mathrm{~g} \mathrm{~L}^{-1}$ de carvão ativado. $\mathrm{O}$ pH do meio de cultura foi ajustado para 5,7 $\pm 0,1$ antes da autoclavagem. As sementes foram mantidas em sala de crescimento com temperatura de $25 \pm 2^{\circ} \mathrm{C}$, fotoperíodo de 12 horas e radiação luminosa de $30 \mathrm{mmol} \mathrm{m}^{-2} \mathrm{~s}^{-1}$, fornecidas por lâmpadas fluorescentes do tipo luz do dia (Sylvania, 20W).

As observações referentes à germinação das sementes foram realizadas diariamente nos primeiros 30 dias de cultivo e mensalmente, durante cinco meses, totalizando seis meses de avaliação. Para avaliar possíveis diferenças na capacidade de proliferação in vitro do algodão-do-campo, dez 
indivíduos provenientes de sementes foram selecionados ao acaso e avaliados comparativamente quanto ao crescimento e taxa de multiplicação.

Para os estudos de conservação, segmentos nodais provenientes da etapa de multiplicação in vitro foram inoculados em tubos de ensaio $(25 \times 150 \mathrm{~mm})$ contendo três diferentes concentrações de sais do meio de WPM $(1 / 2,3 / 4$ e Plena) (Lloyd \& Mccown, 1980), suplementados com $10 \mathrm{~g} \mathrm{~L}^{-1}$ de sacarose, $5 \mathrm{~g}$ $\mathrm{L}^{-1}$ de ágar e $1 \mathrm{~g} \mathrm{~L}^{-1}$ de carvão ativado, sendo o $\mathrm{pH}$ ajustado para 5,7 $\pm 0,1$ antes da autoclavagem. Também foram testados três regimes de temperatura de conservação: 10,20 e $25^{\circ} \mathrm{C}$, em câmara de crescimento com fotoperíodo de 12 horas e radiação luminosa de $30 \mathrm{mmol} \mathrm{m}^{-2} \mathrm{~s}^{-1}$, fornecidas por lâmpadas fluorescentes do tipo luz do dia (Sylvania, 20W). Dados sobre altura e número de gemas formadas foram obtidos mensalmente por um período de 90 dias. Ao final deste período, também foi avaliada a percentagem total de crescimento e sobrevivência.

Os dados foram submetidos à análise de variância e as médias comparadas pelo teste de Tukey a $5 \%$ de probabilidade, utilizando-se o programa estatístico SANEST (Zonta \& Machado, 1984).

\section{RESULTADOE DISCUSSÃO}

$O$ lote de sementes submetido à escarificação química com ácido sulfúrico (T1) apresentou percentual de germinação de $93,3 \%$ aos 30 dias após a inoculação, contrastando com apenas 13,3\% de germinação no lote não escarificado (T2) (Figuras 1 e $3 \mathrm{~A}$ ).

Quando se avaliou o percentual de germinação das sementes ao seis meses, verificou-se que a porcentagem de sementes germinadas em T1 permaneceu constante, porém o percentual obtido em T2 foi de $76,6 \%$, sugerindo que as sementes de algodão do campo apresentam um tipo de dormência física, que pode ser superada pelo emprego de escarificação química, como o uso do ácido sulfúrico (Figura 2).

A ocorrência de dormência é um fenômeno bastante comum descrito em sementes de espécies nativas do cerrado, havendo alguns trabalhos que descrevem diferentes formas de superar a dormência em sementes para o estabelecimento de cultivos in
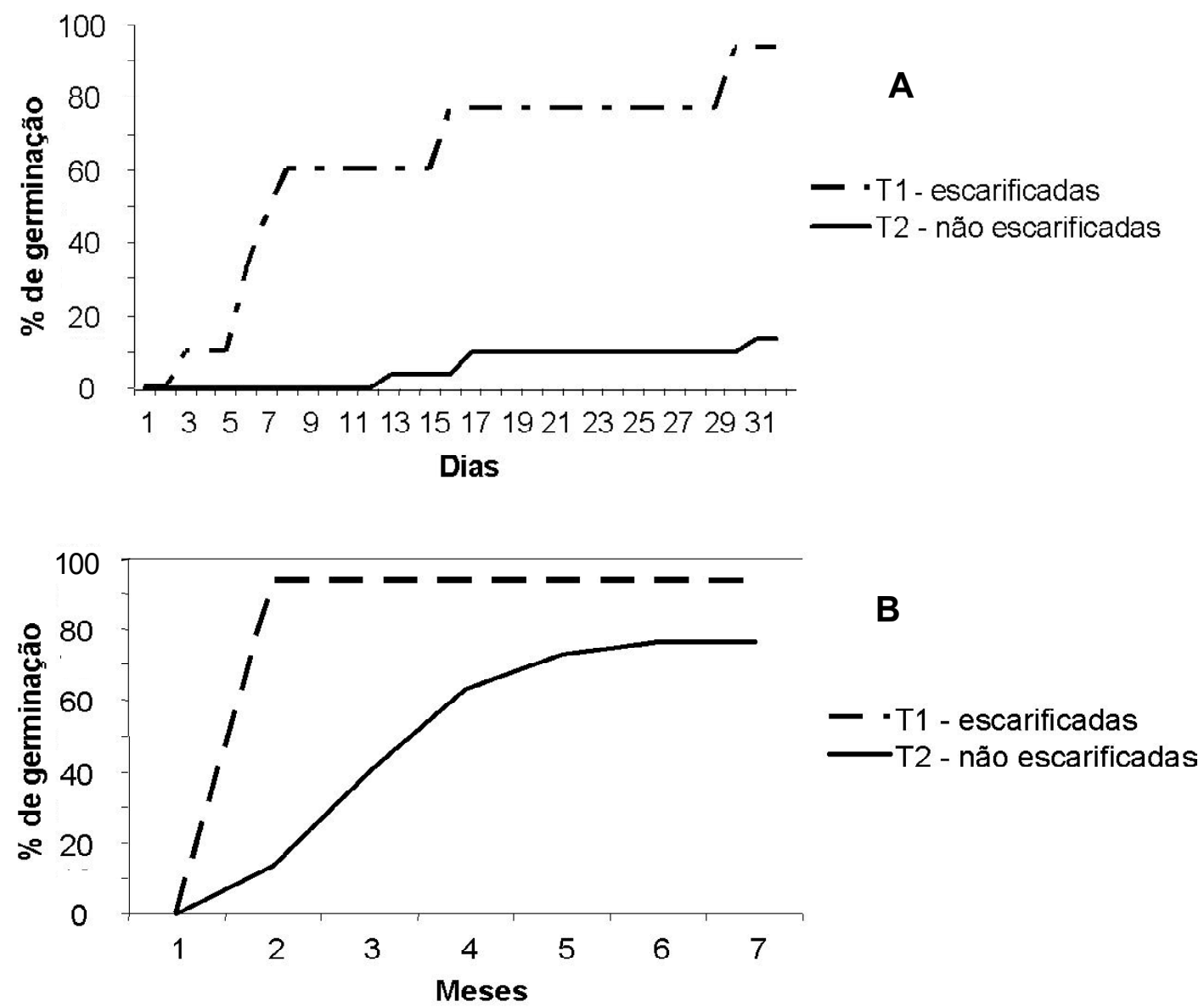

FIGURA 1. Porcentagem de germinação de sementes de Cochlospermum regium após 30 dias (A) e 180 dias (B). O Tratamento 1 (T1) representa as sementes escarificadas em ácido sulfúrico por 40 minutos e o Tratamento 2 (T2) as sementes inoculadas sem escarificação. 
vitro (Coelho et al., 2001; Lima et al., 2007). Noleto \& Silveira (2004) escarificaram mecanicamente sementes de copaíba (Copaifera langsdorffii Desf.) mediante punção na região da testa da semente, obtendo aos 22 dias após a inoculação in vitro percentual de germinação de $75 \%$. Lima et al. (2007) observaram um percentual de germinação in vitro em torno de $60 \%$ em sementes de urucu (Bixa orellana L.), após remoção do tegumento, em meio de MS. Coelho et al. (2001) relataram percentuais de germinação de até $96,7 \%$ em sementes de sucupirabranca [Pterodon pubescens (Benth.) Benth], quando estas foram inoculadas em meio de MS líquido por 35 dias, após a remoção do tegumento.

Na avaliação dos indivíduos foi observado que houve diferença significativa entre os mesmos quanto à altura das brotações e a taxa de multiplicação (Figura 3 B). Aos 60 dias após a inoculação foi obtida uma média de 4,6 gemas formadas, contra apenas 2,7 gemas aos 30 dias de avaliação. A análise da relação entre o número de gemas formadas e o tempo de avaliação, mostrou que, em média, aos 60 dias o número de gemas formadas foi significativamente maior que aos 30 dias. Contudo, a taxa de sobrevivência dos explantes que aos 30 dias foi em média de $96,7 \%$, decresceu para $67,6 \%$ aos 60 dias. Esta diferença no percentual de sobrevivência sugere que é mais vantajoso realizar subcultivos em intervalos menores (30 dias), pois embora a quantidade de gemas obtidas seja menor, o percentual de explantes vivos resultará num maior número de plantas ao final do processo (Tabela 1).

TABELA 1. Influência de plantas originárias de sementes de Cochlospermum regium quanto à altura de brotos, número de gemas formadas e porcentagem de sobrevivência de explantes aos 30 e aos 60 dias de avaliação in vitro

\begin{tabular}{|c|c|c|c|c|c|c|}
\hline \multirow[t]{2}{*}{ Indivíduos } & \multicolumn{2}{|c|}{ Altura $(\mathrm{cm})$} & \multicolumn{2}{|c|}{ Gemas formadas } & \multicolumn{2}{|c|}{ Sobrevivência (\%) } \\
\hline & 30 dias & 60 dias & 30 dias & 60 dias & 30 dias & 60 dias \\
\hline Gp01 & $2,6 a$ & $5,0 \mathrm{a}$ & $4,4 a$ & $7,4 a$ & $83,7 \mathrm{aA}$ & $83,7 \mathrm{abA}$ \\
\hline Gp02 & $1,1 \mathrm{bc}$ & $3,4 \mathrm{bcd}$ & $2,6 a b c$ & $4,0 \mathrm{bc}$ & $87,4 \mathrm{aA}$ & $26,8 \mathrm{bcB}$ \\
\hline Gp03 & $1,9 a b c$ & $4,0 \mathrm{abc}$ & $3,1 \mathrm{abc}$ & $5,1 a b c$ & 100 aA & $83,7 \mathrm{abB}$ \\
\hline Gp07 & $2,1 a b c$ & $4,7 a b$ & $2,8 a b c$ & $5,6 a b$ & $100 \mathrm{aA}$ & $60,8 \mathrm{abcB}$ \\
\hline Gp12 & $1,4 a b c$ & 2,7 cde & $2,9 a b c$ & $4,5 \mathrm{bc}$ & $100 \mathrm{aA}$ & 92,4 aA \\
\hline Gp15 & $1,0 \mathrm{bc}$ & 2,0 de & $1,6 b c$ & $3,4 \mathrm{c}$ & $100 \mathrm{aA}$ & $51,2 \mathrm{abcB}$ \\
\hline Gp17 & $1,4 a b c$ & $3,1 \mathrm{~cd}$ & $2,3 b c$ & $3,3 c$ & 100 aA & $26,0 \mathrm{cB}$ \\
\hline Gp20 & $1,8 \mathrm{abc}$ & $3,0 \mathrm{~cd}$ & $2,6 \mathrm{abc}$ & 4,3 bc & $99,1 \mathrm{aA}$ & 87,4 aA \\
\hline Gp21 & $0,8 \mathrm{c}$ & $1,5 \mathrm{e}$ & $1,5 c$ & $3,6 \mathrm{bc}$ & 96,6 aA & $69,2 \mathrm{abcB}$ \\
\hline Gp22 & $2,4 a b$ & $4,7 a b$ & $3,2 a b$ & $5,1 a b c$ & $100 \mathrm{aA}$ & 94,8 aA \\
\hline Médias & $1,6 \mathrm{~B}$ & $3,4 \mathrm{~A}$ & $2,7 \mathrm{~B}$ & $4,6 \mathrm{~A}$ & $96,7 \mathrm{~A}$ & $67,6 \mathrm{~B}$ \\
\hline
\end{tabular}

Médias seguidas de letras distintas diferem entre si de acordo com o teste de Tukey a $5 \%$ de probabilidade. As letras minúsculas (a,b) comparam as médias no sentido vertical e as letras maiúsculas $(A, B)$ no sentido horizontal

TABELA2. Conservação in vitro de $C$. regium quanto ao percentual de crescimento, altura das plantas e sobrevivência dos explantes submetidos a três regimes de temperatura e três concentrações do meio de cultura WPM.

\begin{tabular}{|c|c|c|c|c|c|c|c|c|c|}
\hline \multirow{2}{*}{$\begin{array}{c}\text { Concentração } \\
\text { WPM }\end{array}$} & \multicolumn{3}{|c|}{ Crescimento (\%) } & \multicolumn{3}{|c|}{ Altura $(\mathrm{cm})$} & \multicolumn{3}{|c|}{ Sobrevivência (\%) } \\
\hline & $10^{\circ} \mathrm{C}$ & $20^{\circ} \mathrm{C}$ & $25^{\circ} \mathrm{C}$ & $10^{\circ} \mathrm{C}$ & $20^{\circ} \mathrm{C}$ & $25^{\circ} \mathrm{C}$ & $10^{\circ} \mathrm{C}$ & $20^{\circ} \mathrm{C}$ & $25^{\circ} \mathrm{C}$ \\
\hline $1 / 2$ & $61,6 a B$ & $54,5 \mathrm{aB}$ & $178,9 \mathrm{bA}$ & $0,7 \mathrm{aB}$ & $0,9 a A$ & $1,5 \mathrm{bA}$ & $4,3 b B$ & $100 \mathrm{aA}$ & $90,4 \mathrm{bA}$ \\
\hline $3 / 4$ & $55,8 a B$ & $53,1 \mathrm{aB}$ & $174,5 \mathrm{bA}$ & $0,7 \mathrm{aB}$ & $0,9 \mathrm{aB}$ & $1,4 \mathrm{bA}$ & $25,0 \mathrm{bB}$ & $100 \mathrm{aA}$ & $100 \mathrm{aA}$ \\
\hline Pleno & $57,8 \mathrm{aB}$ & $69,1 \mathrm{aB}$ & $452,5 a A$ & $0,7 \mathrm{aB}$ & $0,9 a B$ & $3,1 \mathrm{aA}$ & $44,8 a B$ & $100 \mathrm{aA}$ & $100 \mathrm{aA}$ \\
\hline Médias & $58,3 B$ & $58,9 B$ & $268,6 \mathrm{~A}$ & $0,7 \mathrm{~B}$ & $0,9 \mathrm{~B}$ & $2,0 \mathrm{~A}$ & $24,7 B$ & $100 \mathrm{~A}$ & $96,8 \mathrm{~A}$ \\
\hline
\end{tabular}

Médias seguidas de letras distintas diferem entre si de acordo com o teste de Tukey a $5 \%$ de probabilidade. As letras minúsculas (a,b) comparam as médias no sentido vertical e as letras maiúsculas $(A, B)$ no sentido horizontal. 


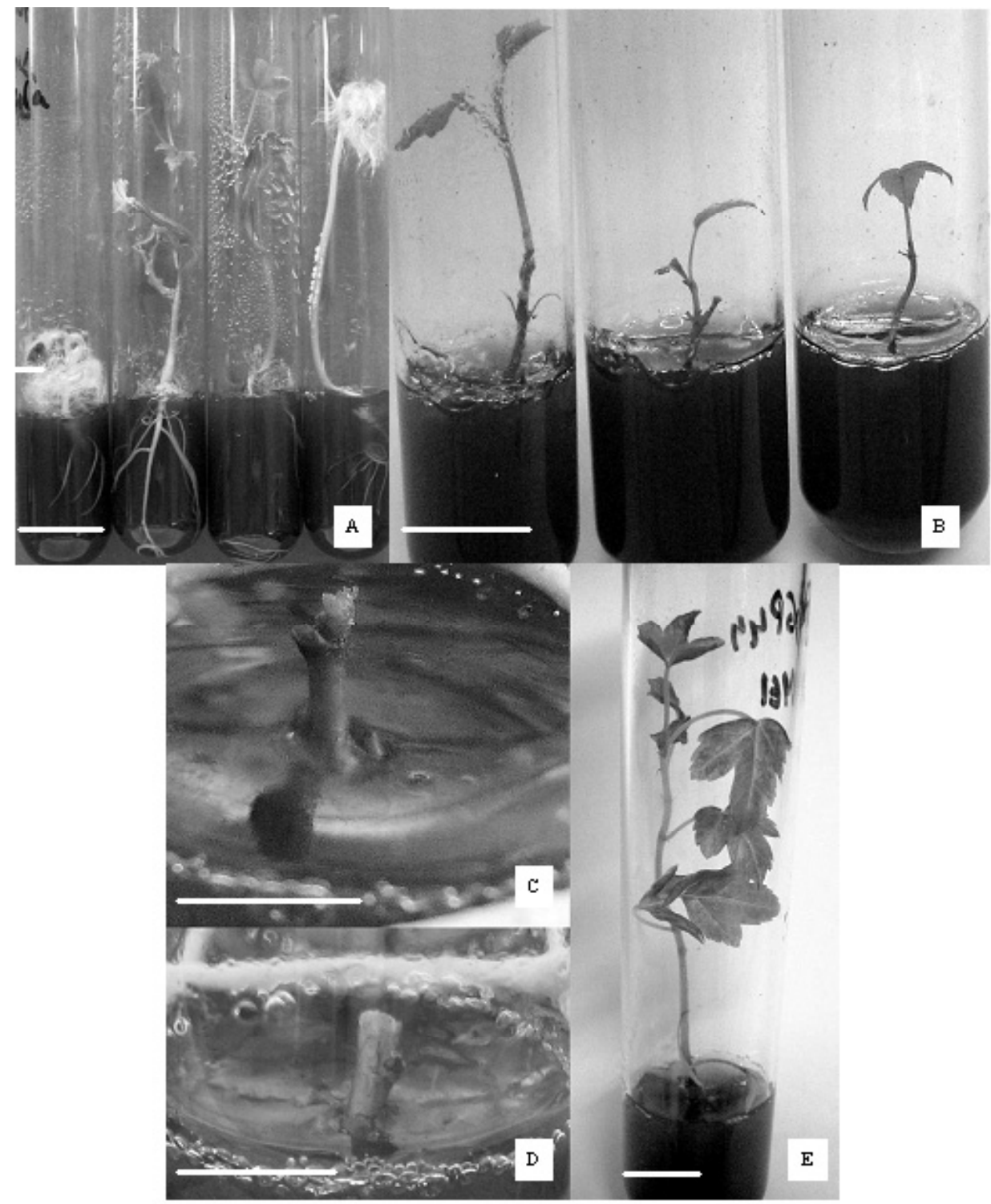

FIGURA 3. Aspecto de plantas de algodão do campo germinadas in vitro (A), da diferença individual do crescimento de plantas originárias de sementes $(\mathbf{B})$ e do crescimento dos explantes quando mantidos em temperaturas de $10^{\circ} \mathrm{C}(\mathbf{C}), 20^{\circ} \mathrm{C}$ (D) e $25^{\circ} \mathrm{C}(\mathbf{E})$. A, B: barra $2 \mathrm{~cm}$; C, D e E: barra $1 \mathrm{~cm}$.

O melhor resultado para conservação in vitro foi obtido com a manutenção dos explantes em meio de cultura $1 / 2$ WPM e em câmara de crescimento com temperatura de $20^{\circ} \mathrm{C}$. Verificou-se que nestas condições a taxa média de crescimento dos explantes foi de $53,1 \%$ e a sobrevivência de $100 \%$ ao final de três meses (Tabela 2 e Figura 3C-E). O meio de cultura utilizado para o experimento de conservação de C. regium foi o WPM, por possuir apenas $45 \%$ da concentração iônica total do meio de MS e concentrações menores de nitrato (MS $40 \mu \mathrm{M}$; WPM 9,7 $\mu \mathrm{M}$ ) e amônio (MS $20 \mu \mathrm{M}$; WPM 4,9 $\mu \mathrm{M}$ ). De acordo com Nunes et al. (2003), o meio WPM apresenta ainda, uma baixa concentração de nitrogênio total $(14,7 \mu \mathrm{M})$ comparado ao MS (60 $\mu \mathrm{M})$, promovendo um crescimento mais lento dos explantes em algumas espécies.

Efeito similar foi observado por Rocha et al. (2007) na micropropagação de canjarana [Cabralea canjerana (Vell.) Mart.]. Ao comparar os meios de cultura MS e WPM, os autores observaram uma maior taxa de multiplicação $(1,7)$ nos segmentos nodais mantidos em meio MS e 2,5 $\mu \mathrm{MBAP}$, em comparação a taxa de multiplicação obtida em meio WPM $(1,2)$. No cultivo em meio WPM, as taxas de multiplicação foram inferiores a 1,2 em todos os sub-cultivos e nas duas concentrações de BAP $(2,5$ e 5,0 $\mu \mathrm{M})$ testadas. O meio WPM por suas características de menor concentrações de sais, foi utilizado com bons resultados na multiplicação e conservação de espécies nativas, como Zeyheria montana (Mart.) 
(Bertoni, 2003) e Lychnophora pinaster (Mart.) (Souza et al., 2003). Pereira et al. (2003) estabeleceram um protocolo para manutenção de um banco de germoplasma in vitro de catuaba [Anemopaegma arvense (Vell.) Stellfeld ex de Souza]. Os resultados mostraram que plantas cultivadas em meio de MS suplementando com $3 \%$ de sacarose e $4 \%$ de sorbitol, mantidas a temperatura de $18^{\circ} \mathrm{C}$ e fotoperíodo de 12 horas, podem permanecer no mesmo frasco por 6 meses, sem substituição do meio de cultura. Sob estas condições o desenvolvimento dos explantes foi lento e a porcentagem média de sobrevivência de $95 \%$. Bertoni (2003) mostrou que plantas de bolsa-de-pastor (Zeyheria montana Mart.) podem ser conservadas em banco de germoplasma in vitroà temperatura de $18^{\circ} \mathrm{C}$, em meio de cultura WPM suplementado com $2 \%$ de sacarose e $4 \%$ de sorbitol. Nestas condições o índice de crescimento das plantas foi baixo e com sobrevivência superior a $95 \%$.

Os resultados obtidos no presente trabalho, permitiram concluir que, a temperatura de $20^{\circ} \mathrm{C}$ associado ao meio de cultura $1 / 2$ WPM é uma condição eficiente para a manutenção e conservação de explantes de $C$. regium sob regime de crescimento mínimo in vitro.

\section{AGRADECIMENTO}

A Embrapa Recursos Genéticos e Biotecnologia pelo aporte físico e financeiro concedido. Ao Conselho Nacional de Desenvolvimento Científico e Tecnológico (CNPq) pelo apoio ao grupo de pesquisa.

\section{REFERÊNCIA}

ALHO, C.J.R. Desafios para a conservação do cerrado, em face das atuais tendências de uso e ocupação. In: SCARIOT, A.; SOUSA-SILVA, J.C.; FELFILI, J.M. Cerrado: ecologia, biodiversidade e conservação. Brasília: Ministério do Meio Ambiente, 2005. p.15-22.

BERTONI, B.W. Propagação, variabilidade genética e química de Zeyheria montana Mart. 2003. 165p. Tese (Doutorado em Genética e Melhoramento de Plantas) Universidade Estadual de São Paulo - UNESP, Jaboticabal. BRITO, M.A. A estratégia de conservação in situ (Unidades de conservação) e a conservação das plantas medicinais. In: COELHO, M.F.B.; COSTA JUNIOR, P.; DOMBROSKI, J.L.D. Diversos olhares em etnobiologia, etnoecologia e plantas medicinais. Cuiabá: UNICEN, 2003, p.137-48.

CASTRO, D.B. et al. Atividades mutagênica e citotóxica do extrato do Cochlospermum regium (Mart. et Schr) Pilger (algodãozinho-do-campo) em camundongos. Revista Brasileira de Plantas Medicinais, v.6, n.3, p.159, 2004.

CESCHINI, L.; CAMPOS, E.G. Cytotoxic effects of Cochlospermum regium (Mart. et Schr) Pilger aqueous root extract on mammalian cells. Journal of Ethnopharmacology, v.103, n.2, p.302-5, 2006.
COELHO, M.C.F. et al. Germinação de sementes de sucupira-branca [Pterodon pubescens (Benth.) Benth.] in vitro e ex vitro. Ciência e Agrotecnologia, v.25, n.1, p.38-48, 2001.

FERREIRA, M.E.; CALDAS, L.S.; PEREIRA, E.A. Aplicações da cultura de tecidos no melhoramento genético de plantas. In: TORRES, A.C.; CALDAS, L.S.; BUSO, J.A. (Eds.). Cultura de tecidos e transformação genética de plantas. Brasília: EMBRAPA - SPI/ EMBRAPA - CNPH, 1998. 509p.

LIMA, R.V. et al. Germinação in vitro de urucu. Revista Brasileira de Sementes, v.29, n.1, p.171-7, 2007.

LIMA, D.P. et al. A flavanone glycoside from Cochlospermum regium (Mart. et Schr) Pilger. Fitoterapia, v.66, p.545-6, 1995.

LLOYD, G.; MCCOWN, B. Commercially: feasible micropropagation of mountain laurel, Kalmia latifolia, by use of shoot tip culture. International Plant Propagators Society Proceedings, v.30, p.421-7, 1980. MENDONÇA, R.C. et al. Flora Vascular do Cerrado. In: SANO, S.M.; ALMEIDA, S.P. Cerrado. Planaltina: EMBRAPA - CPAC, 1998. p.289-556.

MURASHIGE, T.; SKOOG, F. A revised medium for rapid growth and bioassays with tobacco tissue cultures. Physiologia Plantarum, v.15, p.473-97, 1962.

NOLETO, L.G.; SILVEIRA, C.E.S. Micropropagação de copaíba. Biotecnologia, Ciência \& Desenvolvimento, n.33, p.109-20, 2004.

NUNES, W.B.; CARVALHO, S.Evaluation of the mutagenic potential of Cochlospermum regium in Drosophila melanogaster male germ cells. Genetics and Molecular Biology, v.26, n.4, p.545-9, 2003.

NUNES, G.P. et al. Plantas medicinais comercializadas por raizeiros no centro de Campo Grande, Mato Grosso do Sul. Revista Brasileira de Farmacognosia, v.13, n.2, p.18-27, 2003.

OLIVEIRA, C.C. et al. Antibacterial activity of rhizomes from Cochlospermum regium: preliminary results. Fitoterapia, v.67, n.2, p.176-7, 1996.

PEREIRA, A.M.S. et al. Micropropagation of Anemopaegma arvense: conservation of an endangered medicinal plant. Planta Medica, v.69, p.571-3, 2003.

PEREIRA, A.M.S. Cultura de tecidos de plantas medicinais. In: COELHO, M.F.B.; COSTA JUNIOR, P.; DOMBROSKI, J.L.D. Diversos olhares em etnobiologia, etnoecologia e plantas medicinais. Cuiabá: UNICEN, 2003. p.183-94.

ROCA, W.M.; ARIAS, D.I.; CHÁVEZ, R. Métodos de conservación in vitro del germoplasma. In: ROCA, W.M.; MROGINSKI, L.A. Cultivo de tejidos en la agricultura. Colombia: Centro Internacional de Agricultura Tropical, 1991. 923p.

ROCHA, S.C. et al. Micropropagação de Cabralea canjerana. Revista Árvore, v.31, n.1, p.43-50, 2007.

SOUZA, A.V. et al. Germinação de embriões e multiplicação in vitro de Lychnophora pinaster Mart. Ciência e Agrotecnologia, ed. esp., p.1532-8, 2003.

TOLEDO, M.I. et al. Acute and subacute toxicity of Cochlospermum regium (Mart. et Schr) Pilger. Phytotherapy Research, v.14, p.359-61, 2000.

ZONTA, E.P.; MACHADO, A.A. Sistema de análise estatística para microcomputadores - SANEST. Pelotas: UFPEL, 1984. 138p. 